\title{
A Review on Studies of Marijuana for Alzheimer's Disease - Focusing on CBD, THC
}

\author{
Seok Hee Kim', Jin Won Yang², Kyung Han Kim³, Jong Uk Kim¹, Tae Han Yook ${ }^{1 *}$ \\ ${ }^{1}$ Department of Acupuncture \& Moxibustion Medicine, Korean Medicine Hospital of Woosuk University, Jeonju, Korea \\ ${ }^{2}$ Department of Pharmacology, College of Pharmacy, Woosuk University, Wanju, Korea \\ ${ }^{3}$ Department of Preventive Medicine, College of Korean Medicine, Woosuk University, Jeonju, Korea
}

\section{Key Words}

Marijuana, $\operatorname{CBD}($ Cannabidiol), $\operatorname{THC}(\Delta$-tetrahydrocannabidiol), $\mathrm{AD}$ (Alzheimer's diseas)

\section{Abstract \\ Objectives: This study was to discuss the research trend of dementia treatment using cannabis for the purpose of providing the basis of cannabis use for medical purpos- es in the future.}

Methods: This study searched publications, which were registered to databases or published by Aug 22, 2019, and targeted the full-text or abstracts of these publications. We selected the final nine studies met all selection criteria.

Results: These results implied that the CBD components of cannabis might be useful to treat and prevent $\mathrm{AD}$ because $\mathrm{CBD}$ components could suppress the main causal factors of $\mathrm{AD}$. Moreover, it was suggested that using $\mathrm{CBD}$ and THC together could be more useful than using CBD or THC alone.

Conclusion: We hope that there will be a solid foundation to use cannabis for medical use by continuously

$\overline{\text { Received: May 12, } 2019 \text { Reviewed: Jun 11, } 2019 \quad \text { Accepted: Nov 25, } 2019}$

$(0$ This is an Open-Access article distributed under the terms of the Creative Common Attribution Non-Commercial License (http://creativecommons.org/licenses/by-nc/4.0/) which permits unrestricted noncommercial use, distribution, and reproduction in any medium, provided the original work is properly cited.

( This paper meets the requirements of KS X ISO 9706, ISO 9706-1994 and ANSI/NISO Z39.48-1992 (Permanence of Paper). evaluating the possibility of using cannabis for clinical purposes as a dementia treatment substance and cannabis can be used as a positive tool.

\section{Introduction}

The interest in senile disease is rising gradually because aging society has become a more common phenomenon. Types of dementia include AD, vascular dementia, paralytic dementia, Lewy body dementia, carbon monoxide induced dementia, and trauma dementia $[1,2]$. The onset of $\mathrm{AD}$ has continued to increase since 1995, while the prevalence of vascular dementia is gradually decreasing. Therefore, $\mathrm{AD}$ draws attention from researchers [3]. $\mathrm{AD}$ is a disease that is caused by the gradual degeneration and death of cerebral cortical cells. The main symptoms are memory loss, cognitive decline and behavioral disorders [4]. Histopathologically, overall encephalatrophy, senile plaques, and neurofibromatosis (NFT) are the common characteristics of $\mathrm{AD}$ [5]. Acquired cognitive deficits caused by AD have a significant impact on the social life and activity of the patients [6]. Moreover, active treatment of memory disorders greatly affects the prognosis of $\mathrm{AD}$ patients [3]. Consequently, many researchers acknowledge the need for a therapeutic drug to restore the memory and cognitive damages of $\mathrm{AD}$ patients, and various studies have been conducted.

There are three Cannabis species: C. sativa, C. indica,

*Corresponding Author

Tae Han Yook. Department of Acupuncture \& Moxibustion Medicine, Korean Medicine Hospital of Woosuk University, 46, Eoeun-ro, Wansan-gu, Jeonju 54987, South Korea. Phone: +82-063-220-8622

E-mail: nasiss@naver.com 
and C. ruderalis [7]. Cannabidiol (CBD), which is attracting attention as medical cannabis, belongs to cannabinoids [8]. Cacao, the main ingredients of chocolate, and the caryophyllene of black pepper also belong to cannabinoids [9].

Cannabis contains at least 113 kinds of cannabinoids. THC ( $\Delta$-tetrahydrocannabidiol), CBD, CBG (Cannabigerol), and CBN (Cannabinol) are well-known cannabinoids and many studies have been conducted on them. [10] using rats have shown that THC killed cancer cells and reduced tumor size. It has been reported that $\mathrm{CBG}$ expands blood vessels and protects the nervous system [11]. Since CBN is effective for inflammation, pain control, and insomnia, patches containing CBN ingredients are commercially available for human use [12]. Despite these advantageous effects, its use is currently restricted in South Korea according to the Narcotics Control Act (Law No. 15939) in order to prevent health hazards due to drug abuse. However, cannabis is legally used for medical or recreational purposes in several states of the US [13]. Although the medical efficacy and effects of cannabis have been actively studied, cannabis research is quite lacking in South Korea. Therefore, the objective of this study was to discuss the research trend of dementia treatment using cannabis for the purpose of providing the basis of cannabis use for medical purposes in the future.

\section{Materials and Methods}

\subsection{Search Method}

This study searched publications, which were registered to databases or published by Aug 22, 2019, and targeted the full-text or abstracts of these publications. Three researchers independently searched electronic journals in EMBASE and Pubmed. Literature was searched using the keywords of "P(patient)\&I(intervention)". The search terms $\mathrm{P}$ and I are presented in Table 1 . After conducting a literature search, the lists of literature were merged into one document.

\subsection{Selection criteria and outcome assess- ment}

This study selected published studies using Cannabis sativa and its components for patients with dementia. The three researchers independently selected and excluded publications. When there was a discrepancy among them, all researchers discussed whether to include or exclude the publication. The extracted literature was analyzed first by in vivo and in vitro methods, and then by cannabis components used, and by subjects used to determine therapeutic effects.

\section{Results}

\subsection{Description of the included studies}

A total of 1,149 studies were searched through P \& I cross-search, and 86 studies were identified after excluding duplicated studies. We first excluded studies that were not related with dementia or did not use Cannabis sativa and its components using the titles and abstracts of these publications and 21 were selected after the first screening. Afterward, we examined the contents of these 21 studies, five studies failed to obtain full text, five could not determine the efficacy of cannabis on dementia, and two were related to policy. Finally the final nine studies met all selection criteria [14-22] were selected (Fig. 1).

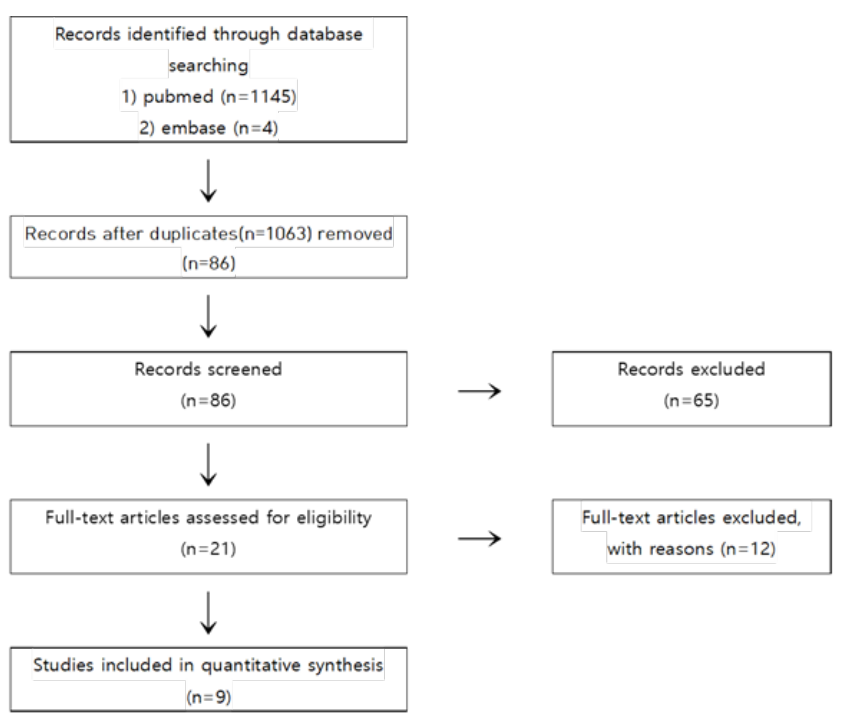

Figure 1 Flowchart of trial selection process

\subsection{In vitro studies using $C B D$ for $A D$}

Four out of five in vitro studies using CBD were performed on PC12 neuronal cells. The results showed that CBD activated the Peroxisome Proliferator-Activated Receptor- $\gamma(\mathrm{P}-$ PARY) through the Wnt/ $\beta$-catenin pathway. As a result, it protected PC12 cells from $A \beta$ neurotoxicity and oxidation stress, increased cell survival, reduced ROS production, reduced lipid peroxidation, inhibited the hyperphosphirylation of tau protein, and inhibited AChE [14-17]. A study conducted on SH-SY5YAPP+ cells showed that it reduced $\mathrm{A} \beta$ production and actually decreased the APP full length protein levels. Additionally, CBD affected the selective activation of PPARY[18].

\subsection{In vivo studies using $C B D$ for $A D$}

Two in-vitro studies using CBD treated the right dorsal hippocampus of mice with human $A \beta(1-42)$ peptide and applied CBD to evaluate the effects of CBD on neurotoxicity and inflammation. The results showed that CBD significantly inhibited the expression of GFAP, mRNA, and protein and reduced the expression of iNOS and IL-1 $\beta$ protein.19) Moreover, the effects of CBD were confirmed 
Table 1 Molecular Targets in Rheumatoid Arthritis

\begin{tabular}{l}
\hline \hline List \\
\hline \hline 'Alzheimer's Disease', 'Dementia, Senile', 'Senile Dementia', 'Dementia, \\
Alzheimer Type', 'Alzheimer Type Dementia', 'Alzheimer-Type Dementia \\
(ATD)', 'Alzheimer Type Dementia (ATD)', 'Dementia, Alzheimer-Type \\
(ATD)', 'Alzheimer Type Senile Dementia', 'Primary Senile Degenerative \\
Dementia', 'Dementia, Primary Senile Degenerative', 'Alzheimer Sclerosis', \\
'Sclerosis, Alzheimer', 'Alzheimer Syndrome', 'Alzheimer Dementia', \\
'Alzheimer Dementias', 'Dementia, Alzheimer', 'Dementias, Alzheimer', \\
'Senile Dementia, Alzheimer Type', 'Acute Confusional Senile Dementia', \\
'Senile Dementia, Acute Confusional’, 'Dementia, Presenile', 'Presenile \\
Dementia', 'Alzheimer Disease, Late Onset', 'Late Onset Alzheimer Disease', \\
'Alzheimer's Disease, Focal Onset', 'Focal Onset Alzheimer's Disease', \\
'Familial Alzheimer Disease (FAD)', 'Alzheimer Disease, Familial (FAD)', \\
'Alzheimer Diseases, Familial (FAD)', 'Familial Alzheimer Diseases (FAD)', \\
'Alzheimer Disease, Early Onset', 'Early Onset Alzheimer Disease,, 'Presenile \\
Alzheimer Dementia'
\end{tabular}

with and without the antagonist of PPARy [20]. It was found that the blocking of PPARy mitigated the effects of CBD on neural damage and CBD stimulated the neurogenesis of the hippocampus through interactions [20].

\subsection{In vivo studies using CBD-THC for AD}

Two in-vivo studies using CBD and THC at the same time showed that the $\mathrm{CBD}+\mathrm{THC}$ treatment was effective on the memory of $\mathrm{A} \beta \mathrm{PP} / \mathrm{PS} 1$ transgenic mice and the CBD+THC was more effective than CBD alone or THC alone treatments [21]. Moreover, the CBD+THC treatment reduced the GluR2/3 of aged AßPP/PS1 mice and increased the level of GABA-A Ral [22].

\section{Discussion}

The number of patients with dementia has been increasing gradually and it is predicted that it will reach 81.1 million in 2040 [23]. It is also forecasted that the number of patients with dementia will be 800,000 in South Korea in 2020 [24]. Additionally, the Ministry of Health and Welfare estimates that about $10 \%$ of the population aged 65 or older will suffer from dementia in 2025 and it will cost 30 tril- lion KRW to treat them [25]. However, we yet do not have a solid treatment to cure dementia and the current standard medications mainly focus only on delaying dementia and recovering symptoms [26].

Therefore, we conducted this study to provide a basis for the treatment of dementia using cannabis, which is currently illegal in South Korea but known to be effective against neuroinflammation, while an effective method is needed for treating dementia, which is gradually becoming a social problem.

This study conducted P\&I cross-search targeting publications published or registered to databases by Aug 22, 2019, using the full-text and abstracts of publications. Finally, nine studies [14-22] were selected and analyzed.

The results of these studies confirmed that CBD activated the peroxisome proliferator-activated receptor- $\mathrm{\gamma}$ (PPARY) through the Wnt/ $\beta$-catenin pathway to protect PC12 cells from $A \beta$ neurotoxicity and oxidation stress, increase cell survival, reduce ROS production, reduce lipid peroxidation, inhibit the hyperphosphirylation of tau protein, inhibit AChE, and stimulate the neurogenesis of the hippocampus.

Additionally, CBD+THC treatment to A $\mathrm{PP} / \mathrm{PS} 1$ transgenic mice revealed that $\mathrm{CBD}+\mathrm{THC}$ treatment was effective in memory and $\mathrm{CBD}+\mathrm{THC}$ treatment was more effective than CBD alone or THC alone treatment. These results implied that the CBD components of cannabis might be 
Table 2 Summary of the effects of CBD and CBD-THC combinations on AD

\begin{tabular}{|c|c|c|c|}
\hline No. & Study ID & Model & Effect \\
\hline \multicolumn{4}{|c|}{ IN VITRO STUDIES USING CBD } \\
\hline 1 & $\begin{array}{l}\text { Iuvone } \\
2004\end{array}$ & PC12 Neuronal Cells & $\begin{array}{c}\text { Protected against } A \beta \text { neurotoxicity and oxidative } \\
\text { stress, increased cell survival and decreased ROS } \\
\text { production and lipid peroxidation }\end{array}$ \\
\hline 2 & $\begin{array}{l}\text { Esposito } \\
2006\end{array}$ & PC12 Neuronal Cells & Inhibited tau hyperphosphorylation \\
\hline 3 & $\begin{array}{l}\text { Eubanks } \\
2006\end{array}$ & PC12 Neuronal Cells & Prevented transcription of pro-inflammatory genes \\
\hline 4 & $\begin{array}{l}\text { Alexandre } \\
2017\end{array}$ & PC12 Neuronal Cells & $\begin{array}{c}\text { A } \beta \text {-induced tau protein hyperphosphorylation is } \\
\text { inhibited }\end{array}$ \\
\hline 5 & $\begin{array}{l}\text { Scuderi } \\
2014\end{array}$ & SH-SY5YAPP+ Cells & $\begin{array}{c}\text { Induced APP ubiquination and subsequently A } \beta \\
\text { production and increased cell survival by reducing } \\
\text { apoptotic rate }\end{array}$ \\
\hline \multicolumn{4}{|c|}{ IN VIVO STUDIES USING CBD } \\
\hline 6 & $\begin{array}{l}\text { Esposito } \\
2007\end{array}$ & $\begin{array}{l}\text { Mice inoculated with } \\
\text { human Aß42 peptide }\end{array}$ & $\begin{array}{l}\text { Attenuated A } \mathrm{B} \text { induced neuroinflammatory } \\
\text { responses by decreasing expression of pro- } \\
\text { inflammatory gene and mediators }\end{array}$ \\
\hline 7 & $\begin{array}{l}\text { Giuseppe } \\
2011\end{array}$ & $\begin{array}{l}\text { Mice inoculated with } \\
\text { human } A \beta 42 \text { peptide }\end{array}$ & Reduced reactive gliosis \\
\hline \multicolumn{4}{|c|}{ IN VIVO STUDIES USING CBD-THC } \\
\hline 8 & $\begin{array}{l}\text { Ester } \\
2015\end{array}$ & $\begin{array}{l}\text { Young APPxPl } \\
\text { transgenic } \quad \text { mice } \\
\text { (mixed background) }\end{array}$ & $\begin{array}{l}\text { Improved memory deficits in the two-object } \\
\text { recognition task and the active avoidance task. } \\
\text { Decreased soluble Aß42 levels and changed plaque } \\
\text { composition and reduced a strogliosis, microgliosis } \\
\text { and inflammatory related molecules }\end{array}$ \\
\hline 9 & $\begin{array}{l}\text { Ester } \\
2016\end{array}$ & $\begin{array}{l}\text { Aged } \quad \text { APPxPS1 } \\
\text { transgenic } \quad \text { mice } \\
\text { (mixed background) }\end{array}$ & $\begin{array}{c}\text { APP/PS1 mice are associated with reduced GluR2/3 } \\
\text { and increased levels of GABA-A R } \alpha 1 \text { in cannabinoid- } \\
\text { treated animals }\end{array}$ \\
\hline
\end{tabular}


useful to treat and prevent $\mathrm{AD}$ because $\mathrm{CBD}$ components could suppress the main causal factors of $\mathrm{AD}$. Moreover, it was suggested that using CBD and THC together could be more useful than using CBD or THC alone.

We hope that there will be a solid foundation to use cannabis for medical use by continuously evaluating the possibility of using cannabis for clinical purposes as a dementia treatment substance and cannabis can be used as a positive tool.

\section{Conflicts of Interest}

The authors have no conflicts of interest to declare.

\section{Acknowledgement}

This study was supported by the National Research Foundation of Korea (NRF) grant funded by the Korea government (MSIP) (No. NRF-2018R1D1A1B07044595).

\section{References}

1. Kim GN, Bae HS, Hwang EW, Jo SH. Study on the Application of Oriental Medical Evaluation to Dementia. JPPKM. 2014;25(4):383-8.

DOI : $10.7231 /$ jon.2014.25.4.383

2. Park MS, Kim YM. Study on Syndrome Differentiation of Dementia. JPPKM. 2014;28(3):251-62. DOI : 10.15188/kjopp.2014.06.28.3.251

3. Han DY, Park NE, Kim SH, Jeong DG. The Effect of Oral Administration of Herbal Medicines on Memory in Alzheimer's Disease Animal Models: A Review of Animal Study Reports Published in Korea. JPPKM. 2017;28(4):359-71.

4. Goedert, M. \& Spillantini, M.G. A century of Alzheimer's disease. Science. 2006;314(5800):777-81.

DOI : $10.1126 /$ science. 1132814

5. Oide T, Kinoshita T, Arima K. Regression stage senile plaques in the natural course of alzheimer's disease. Neuropathology and Applied Neurobiology. 2006;32(5):539-56.

DOI : $10.1111 /$ j.1365-2990.2006.00767.x

6. Qaseem A, Snow V, Cross J, Forciea M, Hopkins R, Shekelle $\mathrm{P}$, et al. Current pharmacologic treatment of dementia: a clinical practice guideline from the American College of Physicians and the American Academy of Family Physicians. Ann Intern Med. 2008;148(5):3708.

DOI : 10.7326/0003-4819-148-5-200803040-00008

7. Patricia R, Joseph S. Medical Marijuana and pain management. Peer-reviewed excellence in life care planning. 2019;19(3):20-5.

DOI : 10.1016/j.disamonth.2016.05.014

8. Ha SY. Perception Survey of the Use of Medical Marihuana Targeting Cancer-Patients and each of their Protectors. 2018, Korea:Hansung Univ. [in dissertation]

9. Won SW. Medical Cannabis, Why Legalize?. Seoul:Saeng-gagbihaeng, 2017.

10. Takeda S, Ikeda E, Su S, Harada M, Okazaki H, Yoshioka Y, et al. Delta(9)-THC modulation of fatty acid 2-hy- droxylase (FA2H) gene expression: Possible involvement of induced levels of PPAR alpha in MDA-MB-231 breast cancer cells. Toxicology. 2014;326(4):18-24. DOI : 10.1016/j.tox.2014.09.011.

11. Deiana S, Watanabe A, Yamasaki Y, Amada N, Arthur $\mathrm{M}$, Fleming S, et al. Plasma and brain pharmacokinetic profile of cannabidiol (CBD), cannabidivarine (CBDV), $\Delta$-tetrahydrocannabivarin (THCV) and cannabigerol (CBG) in rats and mice following oral and intraperitoneal administration and CBD action on obsessive-compulsive behaviour. Psychopharmacology. 2012;219(3):15.

DOI : $10.1007 /$ s00213-011-2415-0

12. Hong TH. Medical hemp. Seoul:Yeongmun, 2017.

13. Vidot DC, Prado G, Hlaing WM, Arheart KL, Messiah SE. Emerging issues for our nation's health: the intersection of marijuana use and cardiometabolic disease risk. J Addict Dis. 2014;33(1):1-8.

DOI : 10.1080/10550887.2014.882718.

14. Iuvone T, Esposito G, Esposito R, Santamaria R, Di Rosa M, Izzo AA. Neuroprotective effect of cannabidiol, a non-psychoactive component from Cannabis sativa, on $\beta$-amyloid-induced toxicity in PC12 cells. J Neurochem. 2004;89(1):134-41. DOI : $10.1111 /$ j.1471-4159.2003.02327.x

15. Esposito G, De Filippis D, Carnuccio R, Izzo AA, Iuvone T. The marijuana component cannabidiol inhibits beta-amyloid-induced tau protein hyperphosphorylation through Wnt/beta-catenin pathway rescue in PC12 cells. J Mol Med. 2006;84(3):253-8.

DOI : 10.1007/s00109-005-0025-1

16. Eubanks LM, Rogers CJ, Beuscher AE, Koob GF, Olson AJ, Dickerson TJ, et al. A molecular link between the active component of marijuana and Alzheimer's disease pathology. Mol Pharm. 2006;3(6):773-7.

DOI : $10.1021 / \mathrm{mp} 060066 \mathrm{~m}$

17. Alexandre Vallée, Yves Lecarpentier, Rémy Guillevin, Jean-Noël Vallée. Effects of cannabidiol interactions with Wnt/ $\beta$-catenin pathway and PPARy on oxidative stress and neuroinflammation in Alzheimer's disease. Acta Biochim Biophys Sin. 2017;49(10):853-66.

DOI : 10.1093/abbs/gmx073

18. Scuderi C, Steardo L, Esposito G. Cannabidiol Promotes Amyloid Precursor Protein Ubiquitination and Reduction of Beta Amyloid Expression in SHSY5Y APP+ Cells Through PPARy Involvement. Phytother Res. 2014;28(7):1007-13.

DOI : $10.1002 /$ ptr.5095

19. Esposito G, Scuderi C, Savani C, Steardo L, De Filippis $\mathrm{D}$, Cottone $\mathrm{P}$, et al. Cannabidiol in vivo blunts $\beta$-amyloid induced neuroinflammation by suppressing IL-1 $\beta$ and iNOS expression. British Journal of Pharmacology. 2007;151(8):1272-9.

DOI : $10.1038 /$ sj.bjp.0707337

20. Giuseppe E, Caterina S, Marta V, Giuseppina IT, Valentina L, Daniele DF, et al. Cannabidiol reduces $A \beta$-induced neuroinflammation and promotes hippocampal neurogenesis through PPARy involvement. PLOS ONE. 2011;6(12):28668.

DOI : $10.1371 /$ journal.pone.0028668

21. Ester Aso, Alexandre SP, Esteban VL, Rafael M, Isidro 
F. Cannabis-Based Medicine Reduces Multiple Pathological Processes in A $\beta P P / P S 1$ Mice. J Alzheimers Dis. 2015;43(3):977-92.

DOI : $10.3233 /$ JAD-141014.

22. Ester Aso, Pol Andrés-B, Isidro F. Delineating the efficacy of a cannabis-based medicine at advanced stages of dementia in a murine model. J Alzheimers Dis. 2016;54(3):903-12.

DOI : 10.3233/JAD-160533

23. Ferri C, Prince M, Brayne C. Brodaty H, Fratiglioni L, Ganguli M. Global prevalence of dementia: a Delphi consensus study. Lancet. 2005;366(9503):2112-7.

DOI : 10.1007/s00127-004-0729-5

24. Seoul National University Hospital. Nationwide study on the prevalence of dementia in Korea elders. Seoul: Ministry for Health, Welfare and Family affairs. 2008.

25. Ministry of Health and Welfare. The 3rd comprehensive plan for dementia management ('16 '20). Seoul: Ministry of Health and Welfare,.2015.

26. Cho HG, Kang HJ, Go YJ, Park JW, Park SG, Jeong PS, et al. Tendency of Korean Herbal Medicine Prescriptions Used for Dementiain Korean Experimental Researches Mainly about Domestic Dissertations for a Degree. JKMR. 2014:24(4):29-40. 